\title{
Environmental Sensitivity of Milk Production in Extensive Environments: A Comparison of Simmental, Brown Swiss, and Tyrol Grey Using Random Regression Models
}

\author{
H. Bytyqi, ${ }^{, 1}$ J. Ødegård,† H. Mehmeti, ${ }^{*}$ M. Vegara,‡ and G. Klemetsdal† \\ *Department of Livestock and Veterinary Sciences, Agriculture Faculty of Prishtina, University of Prishtina-Kosovo, Rr. "Lidhja e Pejes" 38000, \\ Prishtina, Kosovo \\ †Department of Animal and Aquacultural Sciences, and \\ $\ddagger$ Noragric, Norwegian University of Life Sciences (UMB), PO Box 5003, N-1432 Ås, Norway
}

\begin{abstract}
A total of 25,160 milk test-day records from 2,516 cows in first lactation of 3 dairy cattle breeds [Simmental $(\mathrm{n}=1,900)$, Brown Swiss $(\mathrm{n}=444)$, and Tyrol Grey $(\mathrm{n}=172)$ ] in Kosovo were analyzed using nested repeatability and random regression test-day models with varying (co)variance structures. The different models were compared based on likelihood-based criteria. The best model was a second-order random regression model, with heterogeneous cow variance per breed and heterogeneous residual variance per lactation month and breed, which was used for further analysis. The highest milk production was found in Brown Swiss, followed by Simmental and Tyrol Grey. Substantial breed differences were found for the trajectories of cow and residual variances by month of lactation, with the highest variances found for Brown Swiss, followed by Simmental and Tyrol Grey. High cow and residual variances indicated a high degree of environmental sensitivity on the macro- and microenvironmental levels, respectively. Thus, these results indicate increased environmental sensitivity for breeds with higher genetic potential for milk production. These results support the conclusion that dairy cattle production under the current environmental conditions of Kosovo should be based on a breed with moderate production that is robust to the diet offered (e.g., Tyrol Grey).
\end{abstract}

Key words: breed comparison, genotype by environmental interaction, milk yield, test-day model

\section{INTRODUCTION}

After the Kosovo war in 1999, the Food and Agriculture Organization and the World Bank implemented a restocking project in Kosovo by importing heifers from

Received May 18, 2006.

Accepted March 8, 2007.

${ }^{1}$ Corresponding author: hysenbytyqi@hotmail.com
3 dual-purpose cattle breeds: Simmental (SM), Brown Swiss (BS), and Tyrol Grey (TG). The imported heifers were randomly allocated to small-scale farmers, 1 per farm. In Kosovo, cattle production is predominantly small scale and semiextensive (95\%), with herd size and farm averages of, respectively, 2.4 cows and 1.5 ha, having small diversity of feed resources and limited possibilities for grazing. Production is usually consumed on-farm. In this extensive environment, a previous study has revealed that BS had the highest 305-d milk yield and TG the lowest, whereas for indicators of energy balance and fertility (i.e., BCS and service period), TG had the best performance, followed by BS for service period and SM for BCS (Bytyqi et al., 2005). Because the breeds differed in size, they were also compared for their milk production efficiency by calculating metabolic BW per kilogram of milk (Bytyqi et al., 2007), with BS ranking first, followed by SM and TG, which had similar efficiencies. These results seem to support the conclusion that dairy cattle production in Kosovo should be based on a breed of small body size, robust to the diet offered.

In an extensive environment, such as that in Kosovo, the available resources will often not be sufficient to meet the requirements of highly productive breeds, causing reduced milk production, as well as high risk of reproductive and metabolic disorders (Stanton et al., 1991; Cienfuegos-Rivas et al., 1999; Calus et al., 2005; Horan et al., 2005). Further, the high-producing breeds may be more sensitive to variable environments; for example, between farms and from season to season, introducing genotype by environment interactions $\mathrm{Ca}$ lus and Veerkamp, 2003; Dillon et al., 2003; Hayes et al., 2003). The average responsiveness of different genotypes to environmental change can be estimated through genotype-specific estimates of among- and within-environment components of variance (Lynch and Walsh, 1998).

The objective of this study was to compare the environmental sensitivity of 3 breeds, by evaluating their 
Table 1. Number of cows and test-day records of milk yield in first lactation for cows of 3 breeds in Kosovo

\begin{tabular}{lcc}
\hline Breed & Cows, $\mathrm{n}$ & $\begin{array}{c}\text { Test-day } \\
\text { records, } \mathrm{n}\end{array}$ \\
\hline Simmental & 1,900 & 19,000 \\
Brown Swiss & 444 & 4,440 \\
Tyrol Grey & 172 & 1,720 \\
Total & 2,516 & 25,160 \\
\hline
\end{tabular}

variance components, using repeatability and random regression test-day models for test-day milk yield.

\section{MATERIALS AND METHODS}

\section{Data}

Test-day milk yield records (Table 1) used in this study were the same as those analyzed by Bytyqi et al. (2007), consisting of 25,160 records (recorded by the farmers) from 2,516 cows (1,900 SM, $444 \mathrm{BS}$, and 172 TG) in first lactation and 3 phases of importation (in the years 2000, 2001, and 2002). In the first phase, SM and BS were imported, where later importations were restricted to SM and TG. The imported cows were random samples from the breed populations in Austria and Germany.

All cows were required to have 10 monthly records, with each record defined as the sum of milk yield in the morning and evening of one specific test-day. Further restrictions were imposed: the first record had to be prior to $30 \mathrm{DIM}$, the last record after $280 \mathrm{DIM}$, and all test-day observations had to be in the interval from 3 to $50 \mathrm{~kg}$ of milk. A total of 2,516 out of 4,400 cows fulfilled all these requirements. The pedigree files of these cows were not available.

\section{Statistical Analysis}

Test-day records of milk yield were analyzed with 7 nested test-day models, including both repeatability and random regression models, with an identical fixedeffect structure. The fixed structure included effects that had significantly $(P<0.05)$ affected 305 -d milk yield in a previous study (Bytyqi et al., 2005). These effects were breed, importation phase $\times$ village, calving month, and gender of household head (socioeconomic variable, from more widows due to war actions). However, as the interest was toward modeling lactation curves of the different breeds, a breed $\times$ lactation month effect was included, replacing the main effect of breed. All models had the following general characteristics:

$$
\begin{gathered}
D M Y_{i j k l m n}=B L M_{i j}+P V_{k}+C M_{l} \\
+H H F_{m}+\sum_{p=0}^{q} r_{p n} Z_{p}(j)+e_{i j k l m n}
\end{gathered}
$$

where $D M Y_{i j k l m n}=$ daily milk yield of cow $n$, of breed $i$, in lactation month $j$, importation phase $\times$ village class $k$, calving month $l$, and gender effect of household head class $m ; B L M_{i j}=$ fixed effect of breed $\times$ lactation month class $i j$, in 30 classes ( 3 breeds and 10 lactation months); $P V_{k}=$ fixed effect of importation phase $\times$ village class $k$, in 176 classes ( 3 phases and 99 villages); $C M_{l}=$ fixed effect of calving month 1 , in 12 classes; $H H F_{m}=$ fixed effect of gender of household head class $m$, in 2 classes; $Z_{p}(j)=$ pth order orthogonal polynomial of lactation month $j ; r_{p n}=$ pth order random regression coefficient of cow $n$ (sum of genetic and environmental effects on a single cow); and $e_{i j k l m n}=$ random residual.

The following models were specified:

$$
\begin{aligned}
\text { REP1 }= & \text { repeatability model with } q=0, \text { assuming } \\
& \text { homogeneous variances for cow and resid- } \\
& \text { ual effects; } \\
\text { REP2 }= & \text { extension of REP1, with heterogeneous re- } \\
& \text { sidual variance for each month of lacta- } \\
& \text { tion; } \\
\text { REP3 }= & \text { extension of REP2, with heterogeneous } \\
& \text { cow variance per breed; } \\
\text { REP4 }= & \text { extension of REP2, with heterogeneous re- } \\
& \text { sidual variance per breed } \times \text { lactation } \\
& \text { month class; } \\
\text { REP5 }= & \text { combination of REP3 and REP4, with het- } \\
& \text { erogeneous cow variance per breed, and } \\
& \text { heterogeneous residual variance per breed } \\
& \times \text { lactation month class; } \\
\text { RR1 }= & \text { extension of REP5 with } q=1 \text { (first-order } \\
& \text { random regression of cow effects); and } \\
\text { RR2 }= & \text { extension of RR1, with } q=2 \text { (second-order } \\
& \text { random regression of cow effects). }
\end{aligned}
$$

All statistical analyses were performed with ASREML software (Gilmour et al., 1999). Random regression models of higher than second order were not fitted due to convergence problems.

\section{Model Comparison}

As all models had the same fixed effects and were nested with respect to random effects; that is, the different models could be compared on the basis of their values for $\log _{e}$ of the restricted maximum likelihood (InREML). Likelihood-ratio tests were used to test differences in model fit. The likelihood-ratio test statistic (LR) for 2 models, $i$ and $j$, with the restricted model $i$ nested within the model $j$, is 
Table 2. Repeatability (REP) and random regression (RR) test-day models and their estimates for ln of restricted likelihood (lnREML), Akaike information criterion (AIC), likelihood-ratio test statistics (LR), and level of significance $(P$-value) compared with the reduced model

\begin{tabular}{lccccc}
\hline Full model & InREML & AIC & $\begin{array}{c}\text { Reduced } \\
\text { model }\end{array}$ & LR & $P$-value \\
\hline REP1 & $-26,685$ & 0 & - & - & - \\
REP2 & $-24,150$ & 5,053 & REP1 & 5,071 & $<0.01$ \\
REP3 & $-24,129$ & 5,090 & REP2 & 41 & $<0.01$ \\
REP4 & $-23,553$ & 6,207 & REP2 & 1,194 & $<0.01$ \\
REP5 & $-23,536$ & 6,236 & REP4 & 32 & $<0.01$ \\
RR1 & $-19,862$ & 13,572 & REP5 & 7,348 & $<0.01$ \\
RR2 & $-17,415$ & 18,448 & RR1 & 4,894 & $<0.01$ \\
\hline
\end{tabular}

${ }^{1} \mathrm{REP} 1$ = homogeneous cow and residual variances; REP2 = homogeneous and heterogeneous cow and residual variances, respectively, the latter by month of lactation; REP3 $=$ heterogeneous cow and residual variances, by breed and month of lactation, respectively; REP4 = homogeneous cow and heterogeneous residual variances, the latter by breed $\times$ lactation month; REP $5=$ heterogeneous cow and residual variances, by breed and breed $\times$ lactation month, respectively.; RR1 $=$ first-order random regression of cow effects, assuming heterogeneous cow and residual variances, by breed and breed $\times$ lactation month, respectively; $\mathrm{RR} 2$ = second-order random regression of cow effects, assuming heterogeneous cow and residual variances, by breed and breed $\times$ lactation month, respectively.

$$
\mathrm{LR}=2[\ln \operatorname{REML}(j)-\ln \operatorname{REML}(i)] \sim \chi_{v_{j}-v_{i}}^{2}
$$

where $\operatorname{lnREML}(i)$ and $\operatorname{lnREML}(j)$ are the $\operatorname{lnREML}$ values of the models to be compared, and $v_{i}$ and $v_{j}$ are the corresponding numbers of (co)variance components in the models.

Models were also compared with the Akaike information criterion (AIC; Akaike, 1973) favoring models with fewer parameters:

$$
\mathrm{AIC}=2\left[\ln \operatorname{REML}(i)-\ln \operatorname{REML}(0)-\left(v_{i}-v_{0}\right)\right]
$$

where $\operatorname{lnREML}(0)$ and $v_{0}$ are, respectively, the $\operatorname{lnREML}$ and number of (co)variance components of the base model (i.e., REP1). For all likelihood-based criteria, the model with the largest values was considered as having the best fit.

\section{Correcting Variance Components for Scale Effects}

To determine whether breed differences in size of variance components could be attributed to scale effects (Falconer and Mackay, 1996), the coefficient of variation (CV) was calculated for each breed as follows:

$$
C V=\frac{\sigma}{y} \times 100
$$

where $\sigma$ is the square root of the estimated variance component for a specific month of lactation in the preferred model, and $\bar{y}$ is the corresponding estimate for $B L M_{i j}$.

\section{RESULTS}

Results for the 7 models for lnREML, LR and its $P$ value, as well as AIC, are shown in Table 2 . Both LR and AIC indicated that the RR2 model should be preferred for statistical analysis of these data. The fixed breed $\times$ lactation month effects describing the lactation curves of the 3 breeds are presented in Figure 1. Throughout lactation, the largest difference in yield was between BS and TG. Furthermore, the curves had a higher peak for BS and SM compared with TG.

Figure 2 shows the estimates of cow variance by month of lactation, generally decreasing throughout

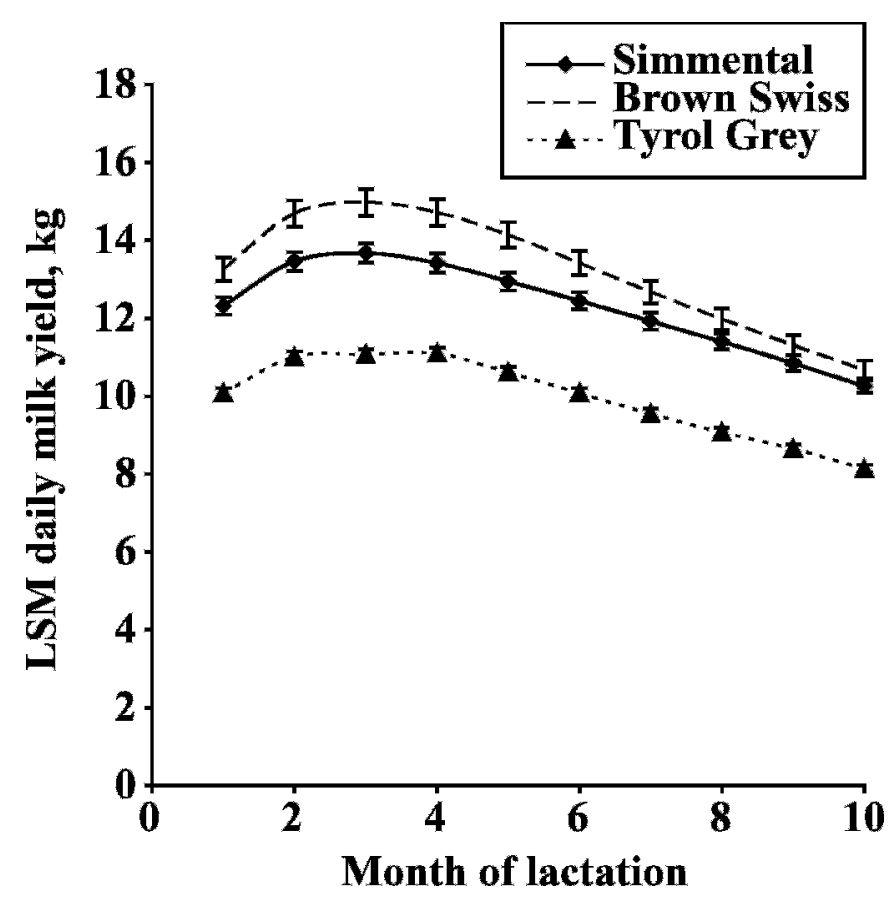

Figure 1. Trajectories of least squares means (LSM), with standard error, for daily milk yield by month of first lactation for Simmental, Brown Swiss, and Tyrol Grey, using a second-order random regression model (RR2) for analysis. 


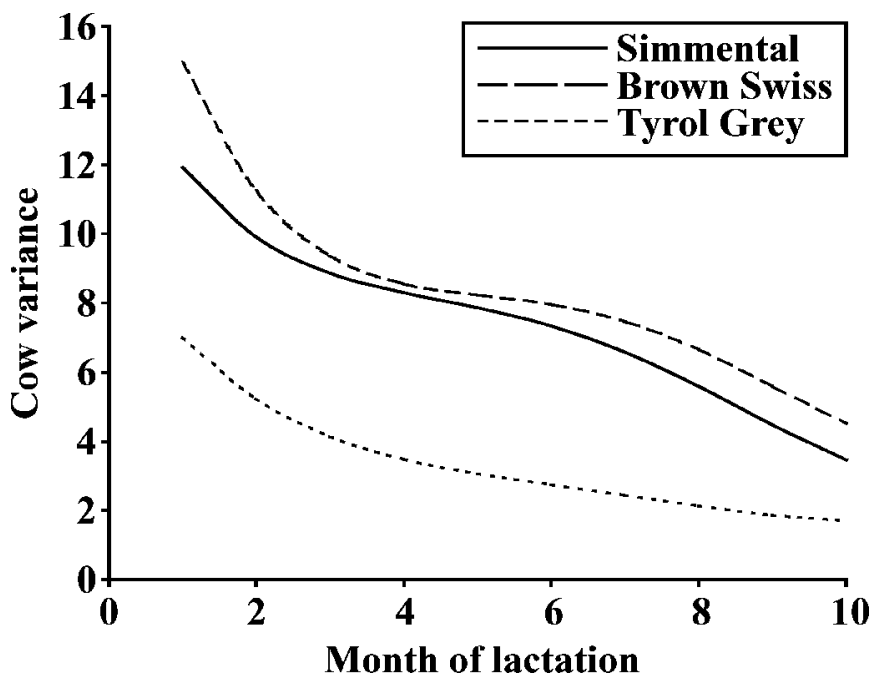

Figure 2. Trajectories of estimated cow variance by month of first lactation for Simmental, Brown Swiss, and Tyrol Grey, using a second-order random regression model (RR2) for analysis.

lactation. However, large and consistent breed differences were observed, with BS having the largest estimates, followed by SM and TG. Residual variances by month of lactation for the 3 breeds are presented in Figure 3, with the largest estimated values in the first half of lactation, diminishing toward the end. As for the cow variance, substantial breed differences were estimated, with the highest values for BS, again followed by SM and TG. Because the ranking of the breeds on size of variance components was identical to their ranking for daily milk yield, these results might be partly explained by scale effects. To account for a possible scale effect, CV for cow and residual effects were

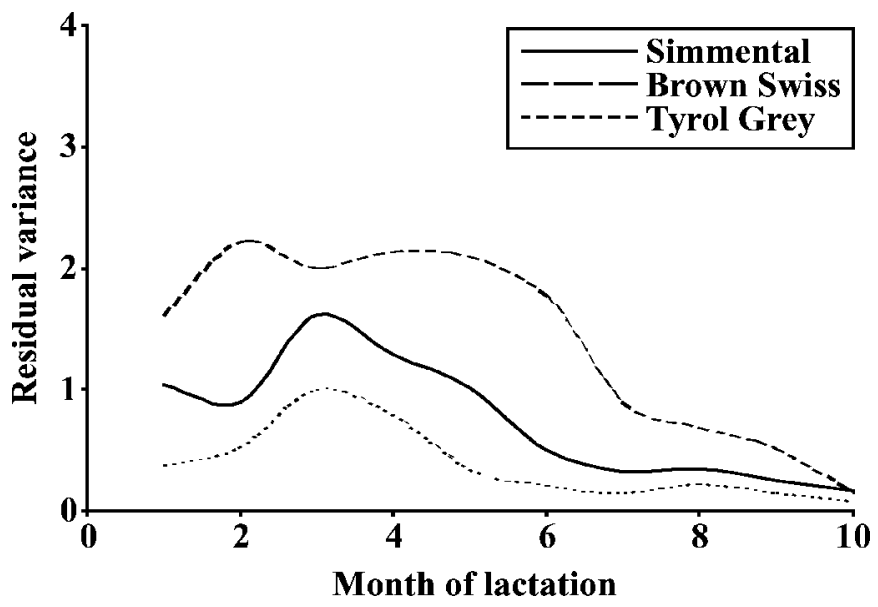

Figure 3. Trajectories of estimated residual variance by month of first lactation for Simmental, Brown Swiss, and Tyrol Grey, using a second-order random regression model (RR2) for analysis.

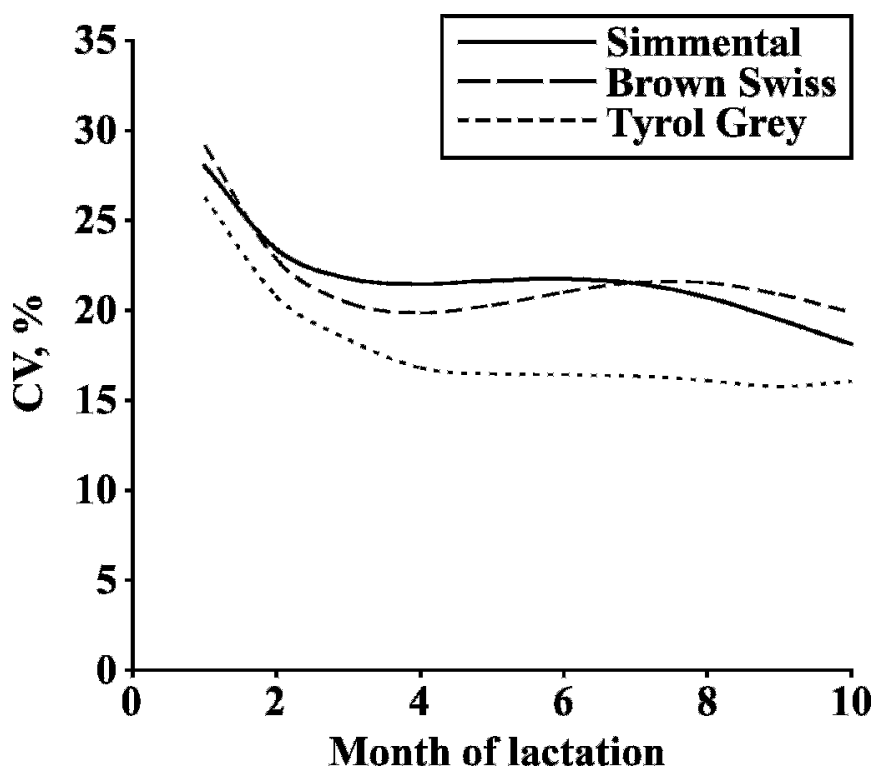

Figure 4. Trajectories of estimated coefficient of variation $(\mathrm{CV})$ for cow effect by month of first lactation for Simmental, Brown Swiss, and Tyrol Grey, using a second-order random regression model (RR2) for analysis.

calculated (Figures 4 and 5, respectively). After correction for scale, clear breed differences existed. Hence, scale effects cannot solely explain these differences.

\section{DISCUSSION}

Despite the fact that the experiment was unbalanced in terms of number of cows of each breed, the heterogeneity of cow and error variances by breed and breed $\times$ lactation month, respectively, significantly improved the modeling of the data. Additional improvement was achieved from a longitudinal specification of the cow effect through random regression, which was expected, because all cows had 10 records. Ideally, records on cows without complete lactations should have been included in the study, but these were not available from the project.

The results showed that both cow and residual variances change during the course of lactation. The pattern of this variation was similar for all breeds, with the largest variance in early lactation at time of peak yield, as has been found in practical large-scale applications (e.g., Jamrozik and Schaeffer, 1997; Strabel and Misztal, 1999).

By calculating the $\mathrm{CV}$, it was shown that the differences in breed variances could not be attributed to scale effects alone. The heterogeneity of the residual and cow variances indicate breed differences in environmental sensitivity to micro- (test-day) and macroenvironmental (herd) change (Lynch and Walsh, 1998), respec- 


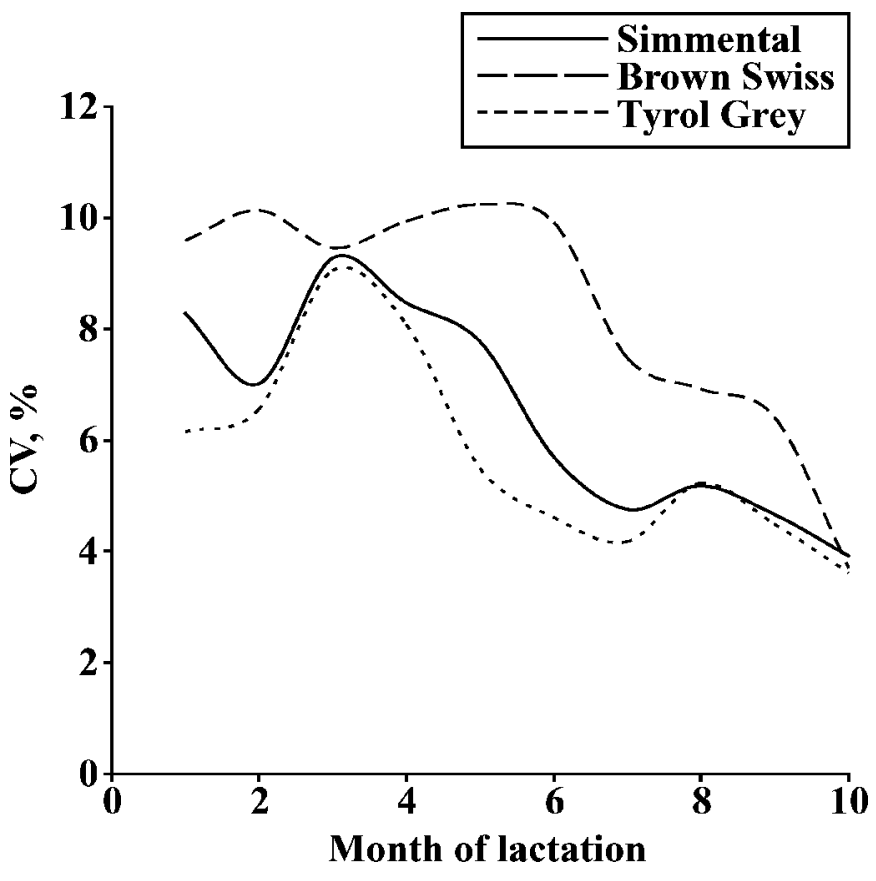

Figure 5. Trajectories of estimated coefficient of variation (CV) for residual effect by month of first lactation for Simmental, Brown Swiss, and Tyrol Grey, using a second-order random regression model (RR2) for analysis.

tively, the latter because a separate herd effect was not modeled. Because breeds were randomly allocated to herds, each breed was exposed to the same range of physical environments. Thus, the estimated cow variance for the breeds approaches the breeds' sensitivity to the same variability of herd environments.

The approach chosen, with examination of heterogeneity of variance components by likelihood-ratio tests, revealed significant differences in environmental sensitivity. The largest variances were estimated for BS, followed by SM and TG; that is, TG was the most phenotypically stable among the breeds studied. The large variance for BS implies larger environmental sensitivity or phenotypic plasticity. This might be advantageous for herds with an improved environment. However, the majority of herds were small and characterized by extensive production on a subsistence level, in which a breed with stable production might be preferred over a breed with high degree of phenotypic plasticity, given that the average production levels are not too different. Ideally, the choice of the best breed for Kosovo should have been based on profit analyses, requiring a rather complete recording of traits. However, because only a few indicator traits were available, the only approach possible for comparing breeds was by studying how well the breeds fitted to the local environments by studying the recorded traits. Bytyqi et al. (2005) found clear differences between these breeds with respect to production level, interval from calving to first insemination, and BCS. Based on this information, it was concluded that TG should be preferred due to its better performance for fertility and energy balance (associated with risk of production diseases), even though production level was lowest in this breed. The stability of milk production of TG compared with the other breeds supports the conclusions of Bytyqi et al. (2005). Thus, given that the production system in Kosovo is mostly small scale and seasonal, factors such as calving interval (approximately $1 \mathrm{yr}$ ) and avoiding unexpected costs (e.g., sudden death, involuntary culling, veterinary treatments, and loss of production due to diseases) will be of high economic importance, and might even exceed the importance of production level.

In the future, the production environment for cows in Kosovo may improve. Without any selective breeding programs in place, the existing cow population should be bred to sires of the best breed under the current environmental conditions. However, to adapt to a changing environment, choice of sire breed needs to be continuously evaluated.

\section{CONCLUSIONS}

Breed heterogeneity of variance components was found for the breeds BS, SM, and TG, with the largest cow and residual variances estimated for BS, followed by SM and TG. Increased variances could not only be attributed to scale effects and thus indicate breed differences with respect to environmental sensitivity (i.e., genotype $\times$ environment interaction). Hence, the breed BS was identified as being the most environmentally sensitive (more phenotypic plasticity) followed by SM and TG (more phenotypic stability). A high degree of environmental sensitivity can be regarded as positive if the environment is likely to improve. However, in a stressful environment where availability of food resources may vary considerably during the year (and the nutritional requirements of a highly productive breed are thus not likely to be met), a stable production level might be preferred over a high degree of phenotypic plasticity. Hence, the results of this study support the conclusion from a previous study (Bytyqi et al., 2005), that despite being the breed with the lowest production level, TG seems best fitted to the currently rough environmental conditions in Kosovo, based on indicators of energy balance and fertility.

\section{ACKNOWLEDGMENTS}

The authors are grateful to the Ministry of Agriculture of Kosovo, World Bank, and FAO for providing 
access to the data. The Research Council of Norway is acknowledged for financial support. Staff members in Kosovo FAO-EFRP and in the Agriculture Faculty of Prishtina are acknowledged for their assistance in the project.

\section{REFERENCES}

Akaike, H. 1973. Information theory as an extension of the maximum likelihood principle. Pages 267-281 in Proc. Second Int. Symp. Informational Theory. B. N. Petrov, and F. Csaki, ed. Akademiai Kiado, Budapest, Hungary.

Bytyqi, H., G. Klemetsdal, J. Ødegård, H. Mehmeti, and M. Vegara. 2005. A comparison of the productive, reproductive and body condition score traits of the Simmental, Brown Swiss and Tyrol Grey breeds in smallholder herds in Kosovo. Anim. Genet. Res. Inf. 37:9-20.

Bytyqi, H., J. Ødegård, M. Vegara, H. Mehmeti, and G. Klemetsdal. 2007. Short communication: Lactation curves and production efficiency for Simmental, Brown Swiss and Tyrol Grey in Kosovo. Acta Agric. Scand., A 56(3/4):161-164.

Calus, M. P. L., M. J. Carrick, R. F. Veerkamp, and M. E. Goddard. 2005. Estimation of genetic parameters for milk fat depression in dairy cattle. J. Dairy Sci. 88:1166-1177.

Calus, M. P. L., and R. F. Veerkamp. 2003. Estimation of environmental sensitivity of genetic merit for milk production traits using a random regression model. J. Dairy Sci. 86:3756-3764.

Cienfuegos-Rivas, E. G., P. A. Oltenacu, R. W. Blake, S. J. Schaweger, H. Castillo-Juarez, and F. J. Ruiz. 1999. Interaction between milk yield of Holstein cows in Mexico and the United States. J. Dairy Sci. 82:2218-2223.

Dillon, P., F. Buckley, P. O'Connor, D. Hegarty, and M. Rath. 2003. A comparison of different cow breeds on a seasonal grass-based system of milk production. 1. Milk production, live weight, body condition score and DM intake. Livest. Prod. Sci. 83:21-33.

Gilmour, A. R., B. R. Bullis, S. J. Welham, and R. Thompson. 1999. ASREML Reference Manual. NSW Agric. Biometric Bulletin no. 3. Orange Agriculture Institute, Orange, New South Wales, Australia.

Falconer, D. S., and T. F. C. Mackay. 1996. Pages 290-298 in Introduction to Quantitative Genetics. 4th ed. Longman, Essex, UK.

Hayes, B. J., M. Carrick, P. Bowman, and M. E. Goddard. 2003. Genotype $\times$ environmental interaction for milk production of daughters of Australian dairy sires from test-day records. J. Dairy Sci. 86:3736-3744.

Horan, B., P. Dillon, P. Faverdin, L. Delaby, F. Buckley, and M. Rath. 2005. The interaction of strain of Holstein-Friesian cows and pasture-based feed systems on milk yield, body weight, and body condition score. J. Dairy Sci. 88:1231-1243.

Jamrozik, J., and R. Schaeffer. 1997. Estimation of genetic parameters for a test day model with random regression for yields traits of first-lactation Holsteins. J. Dairy Sci. 80:762-770.

Lynch, M., and B. Walsh. 1998. Genetics and Analysis of Quantitative Traits. Sinauer Associates Inc., Sunderland, MA.

Stanton, T. L., R. W. Blake, and R. L. Quaas. 1991. Genotype by environment interaction for Holstein milk yield in Columbia, Mexico, and Puerto Rico. J. Dairy Sci. 74:1700-1714.

Strabel, T., and I. Misztal. 1999. Genetic parameters for first and second lactation milk yields of Polish Black and White cattle with random regression test-day model. J. Dairy Sci. 82:2805-2810. 